\title{
PENGARUH ASAM NITRAT TERHADAP LAJU KOROSI BAJA TAHAN KARAT AUSTENITIK 304 UNTUK KEPERLUAN KONSTRUKSI
}

\author{
Drs. M.O.S Aritonang, M.Pd dan lqbal Fahri, S.Pd
}

\begin{abstract}
Abstrak
The purpose of this research is to investigate corrosion rate of austenitic stainless steel type 304 attack nitric acid 65\% with austenitic stainless steel type 304 attack nitric acid 85\% for construction importance. The research was conducted in Material Research Association of Industry Ministry DKI Jakarta Laboratory. The methodology used in this research was experiment with two types of treatments. Those are; first group is austenitic stainless steel type 304 attack nitric acid $65 \%$ and the second group is austenitic stainless steel type 304 attack nitric acid $85 \%$. The amount of all tested instruments are 10 pieces from two types of treatments. For discern influence of corrosion toward mechanical properties of austenitic stainless steel type 304 particularly tensile strenght, executed strength testing toward two group austenitic stanless steel type 304 attack nitric acid. Be sides, executed also strength testing toward one group austenitic stainless steel type 304 as control group. Based on the research, the findings show that austenitic stainless steel type 304 attack nitric acid 65\% has corrosion rate $3,751 \mathrm{~mm} /$ year at the average and austenitic stainless steel type 304 attack nitric acid $85 \%$ has corrosion rate 6,404 mm/year at the average. The data from the research was tested by average test two tails ( $t$ - test), one tail test, the left tail with $\alpha=0,01$, and from the analysis can be got $t_{\text {count }}=-11,53$, the score is smaller than $t_{\text {Table }}=-2,90$ which $H_{0}$ in rejection area. Descending quality of austenitic stainless steel type 304 toward corrosion attack, followed also by descending tensile strenght of austenitic stainless steel type 304. Before corrosion austenitic stainless steel has tensile strenght $60,107 \mathrm{kgf} / \mathrm{mm}^{2}$. After corrosion with nitric acid 65\% tensile strenght austenitic stainless steel type 304 become $57,329 \mathrm{kgf} / \mathrm{mm}^{2}$. Such again, after corrosion with nitric acid $85 \%$ tensile strenght austenitic stainless steel type 304 become $55,349 \mathrm{kgf} / \mathrm{mm}^{2}$.
\end{abstract}

Kata Kunci: baja tahan karat, asam nitrat, laju korosi. 


\section{PENDAHULUAN}

Baja tahan karat jenis Austenitik 304 merupakan salah satu jenis baja tahan karat yang paling tahan terhadap karat jika dibandingkan dengan jenisjenis yang lain. Ketahanan terhadap karat pada baja tahan karat tersebut disebabkan adanya unsur khrom yang lebih dari $12 \%$.

Baja tipe ini sangat populer karena sifat mampu las (weldability) yang lebih baik dan tendensi terjadinya presipitasi karbida khrom lebih rendah sebab hal tersebut dapat menurunkan sifat tahan karat sehingga dapat mendorong terjadinya korosi batas butir."

Baja ini berstruktur austenitik (berada pada fasa austenit), tidak bersifat magnetik, dan non hardenable (tidak dapat dikeraskan dengan perlakuan panas). Baja jenis ini mudah dikerjakan panas, tetapi agak sulit dikerjakan dingin karena dapat mengalami pengerasan. Pengerjaan panas dilakukan dengan cara pengelasan, sedangkan pengerjaan dingin dilakukan dengan cara mencelup cepat baja yang telah dipanaskan di dalam air.

Baja tahan karat austenitik jika dipanaskan pada temperatur $1050^{\circ} \mathrm{C}$ dan dicelupkan cepat di dalam air akan membuatnya stabil berfasa austenitik. Deformasi akibat pengerjaan dingin pada temperatur kamar (biasanya diatas $750^{\circ} \mathrm{C}$ ), akan menyebabkan terjadinya pengerasan regangan (Strain Hardering) disamping itu juga terjadi transformasi fasa dari austenit (FCC) menjadi fasa martensit (BCC).

Kelemahan lainnya apabila dilakukan pengelasan atau bekerja pada rentang temperatur $550^{\circ} \mathrm{C}-850^{\circ} \mathrm{C}$ dan diekspos pada media korosif, maka akan terjadi peristiwa sensitisasi.iii Pada kondisi ini akan terbentuk senyawa khrom karbida pada batas butir, sehingga di sekitar batas butir tidak akan terbentuk lapis lindung khrom oksida, sehingga akan terserang korosi batas butir (Intergranular Corrosion).

Dengan demikian dalam kondisi tertentu, baja tahan karat dapat menjadi mudah terserang korosi dan kadang juga dapat terjadi perubahan fasa, yaitu dari fasa austenit menjadi fasa martensit. Hal ini disebabkan karena perlakuan-perlakuan tertentu pada baja tahan karat tersebut.

Terjadinya korosi batas butir maupun terjadinya perubahan fasa adalah merupakan indikasi menurunnya kemampuan baja tahan karat jenis austenitik 304 terhadap serangan korosi, terutama terhadap lingkungan yang sangat

Pengaruh Asam Nitrat Terhadap Laju Korosi Baja Tahan karat Austenitik 304 untuk Keperluan Konstruksi (MOS. Aritonang, Dosen Jurusan Teknik Sipil FT-UNJ) 
korosif terhadap baja tahan karat.

Pengaruh asam pada daerah industri, akibat larutan-larutan asam yang lemah sebagai hasil dari kondensasi uap dari udara yang bersenyawa dengan uap yang mengandung asam, menyebabkan ketahanan karat pada baja tahan karat Austenitik 304 menurun. Pemakaian larutan asam nitrat dapat secara signifikan mereduksi ketahanan korosi pada baja tahan karat bila prosentase konsentrasi larutannya mencapai dan atau di atas $60 \%$ dengan suhu rata-rata $100^{\circ} \mathrm{C}$.

SNI menetapkan penggunaan asam nitrat $65 \%$ untuk menilai ketahanan baja tahan karat Austenitik terhadap korosi batas butir.

Laju korosi semakin meningkat seiring dengan peningkatan konsentrasi larutan sehingga dapat mencapai batasan yang tidak dapat diterima penggunaannya (unacceptable, $>5 \mathrm{~mm} / \mathrm{yr}$ ). Bila konsentrasi larutan $\mathrm{HNO}_{3}$ mencapai dan atau melebihi $85 \%$ dengan suhu rata-rata $100^{\circ} \mathrm{C}$, maka laju korosi akan terus meningkat dari nilai 0,5 menuju ke nilai 1 (dan atau lebih tinggi dari itu) yang menandakan ketahanan korosi baja tahan karat terus mengalami penurunan.

Kondisi tersebut tentu dapat merugikan pemakai baja tahan karat Austenitik 304 untuk keperluan konstruksi. Akibat buruk ini tentunya tidak hanya menyangkut masalah yang berkaitan dengan segi ekonomi, namun juga terkait dengan masalah jiwa manusia.

Tujuan penelitian ini adalah untuk mengetahui apakah nilai laju korosi baja tahan karat Austenitik 304 yang dikorosikan dengan asam nitrat $65 \%$ lebih kecil daripada nilai laju korosi baja tahan karat Austenitik 304 yang dikorosikan dengan asam nitrat $85 \%$.

\section{Metode Penelitian}

Metode yang akan dipergunakan dalam penelitian ini adalah metode eksperimen di laboratorium. Standar pengujian didasarkan pada ASTM A 26293a atau SNI 07-3112-1992.

\section{Disain Penelitian}

Disain penelitian yang akan dipergunakan adalah baja tahan karat Austenitik 304 yang berbentuk pelat dengan ukuran sebagai berikut: lebar 
(W) 12,5 mm, panjang ukur (L) $50 \mathrm{~mm}$, panjang bagian paralel (P) $60 \mathrm{~mm}$, jari-jari bahu (R) $20 \mathrm{~mm}$, lebar bagi (B) $20 \mathrm{~mm}$, dan tebal $3 \mathrm{~mm}$. Disain benda uji didasarkan pada SNI 07-0371-1989.

\section{Variabel Penelitian}

Pada penelitian ini terdapat dua variabel, yaitu:

a. Variabel bebas dalam penelitian ini adalah variasi persentase asam nitrat yaitu $65 \%$ dan $85 \%$.

b. Variabel terikat penelitian ini adalah nilai laju korosi batas butir pada baja tahan karat Austentitik 304.

\section{Prosedur Penelitian}

Penelitian dilakukan berdasarkan prosedur berikut ini:

a. Benda uji dipanaskan pada temperatur $675^{\circ} \mathrm{C}$. Kemudian ditahan selama 1 jam, dan dicelup cepat ke dalam air.

b. Penimbangan benda uji.

c. Pemasangan 5 benda uji pada mesin uji tarik untuk mengetahui nilai uji tarik sebelum dikorosikan.

d. Pengkorosian 10 benda uji dengan komposisi asam nitrat $\left(\mathrm{HNO}_{3}\right)$ yang berbeda yaitu $65 \%$ dan $85 \%$ (masing-masing 5 benda uji) selama 48 jam dalam 5 periode $(9,6 ; 19,2 ; 28,8 ; 38,4$; dan 48 jam) dengan pergantian larutan setiap periode.

e. Pada setiap periode benda uji dibersihkan dengan pelarut bebas klor seperti sabun atau aseton, dan selanjutnya dikeringkan serta ditimbang dengan ketelitian 0,001 gram.

f. Benda uji yang telah dikorosikan diuji tarik.

g. Hasil uji diamati, dan kemudian dilakukan pembahasan dan disimpulkan.

\section{Teknik Pengambilan Contoh}

Populasi yang diambil dalam penelitian ini adalah nilai laju korosi batas butir pada baja tahan karat Austenitik 304 dengan menggunakan komposisi asam nitrat yang berbeda yaitu 65\% dan $85 \%$. Sampel yang akan dipergunakan dalam penelitian ini sebanyak 15 buah, 5 buah 
dipergunakan untuk uji tarik serta 10 buah untuk uji korosi batas butir dan uji tarik.

\section{Instrumen Penelitian}

Instrumen penelitian yang dipergunakan dalam penelitian ini adalah:

1. Dapur pemanas dengan temperatur maksimum $800^{\circ} \mathrm{C}$.

2. Labu erlenmeyer 1 liter dilengkapi dengan kondensor tipe jari atau kondensor refluks vertikal.

3. Pemegang benda uji.

4. Pemanas listrik yang dapat menjaga larutan uji selalu mendidih selama periode pengujian.

5. Mesin uji tarik.

6. Neraca analitik dengan ketelitian 0,001 gram.

7. Format isian pengumpulan data.

\section{Hasil Penelitian}

Pada penelitian ini telah dilakukan beberapa buah perlakuan terhadap benda uji. Untuk kelompok pertama adalah baja tahan karat Austenitik 304 yang dikorosikan dengan asam nitrat $\left(\mathrm{HNO}_{3}\right)$ 65\% dan kelompok kedua adalah baja tahan karat Austenitik 304 yang dikorosikan dengan asam nitrat $\left(\mathrm{HNO}_{3}\right)$ $85 \%$.

Hasil pengujian-pengujian tersebut secara lengkap dapat dilihat pada tabel 1 di bawah ini.

Tabel 1. Hasil Pengujian Korosi Batas Butir Baja Tahan Karat Austenitik 304

\begin{tabular}{|l|l|l|l|c|c|}
\hline \multirow{2}{*}{$\begin{array}{l}\text { NOMOR } \\
\text { URUT }\end{array}$} & $\begin{array}{l}\text { NOMOR } \\
\text { BENDA } \\
\text { UJI }\end{array}$ & HASIL PENGUJIAN KOROSI BATAS BUTIR (mm/tahun) \\
\cline { 5 - 6 } & & DENGAN HNO & \\
& & & \\
\hline 1 & 6 & 3 & 7 & 3,350 & DENGAN $\mathrm{HNO}_{3} 85 \%$ \\
\hline 2 & 7 & 4 & 8 & 3,645 & 5,822 \\
\hline 3 & 8 & 5 & 10 & 3,673 & 6,364 \\
\hline 4 & 9 & 2 & 9 & 3,862 & 6,430 \\
\hline 5 & 10 & 1 & 6 & 4,226 & 6,443 \\
\hline \multicolumn{2}{|l|}{ RATA - RATA } & 3,571 & 6,962 \\
\hline
\end{tabular}


Dari hasil pengujian korosi batas butir dengan media korosi asam nitrat $\left(\mathrm{HNO}_{3}\right) 65 \%$ pada baja tahan karat Austenitik 304 didapat nilai terendah 3,35 $\mathrm{mm} /$ tahun dan nilai tertinggi 4,226 mm/tahun. Nilai rata-rata laju korosinya adalah $3,751 \mathrm{~mm} /$ tahun. Nilai simpangan baku adalah 0,32 dan nilai varians adalah 0,1024 .

Nilai terendah untuk laju korosi batas butir dengan media korosi asam nitrat $\left(\mathrm{HNO}_{3}\right)$ 85\% adalah 5,822 mm/tahun. Nilai tertingginya adalah 6,962 $\mathrm{mm} /$ tahun. Nilai rata-rata laju korosinya adalah $6,404 \mathrm{~mm} /$ tahun. Nilai simpangan baku adalah 0,404 dan nilai varians adalah 0,1632.

Untuk memperkaya penelitian, dua kelompok benda uji yang telah terkorosi diuji tarik. Pengujian tarik dilakukan untuk mengetahui seberapa besar pengaruh korosi batas butir terhadap sifat mekanik baja tahan karat Austenitik 304 terutama kuat tariknya. Hasil uji tarik secara lengkap dapat dilihat pada Tabel 2.

Baja tahan karat Austenitik 304 sebelum mengalami korosi batas butir memiliki kuat tarik rata-rata $60,107 \mathrm{kgf} / \mathrm{mm}^{2}$. Setelah mengalami korosi batas butir dengan media korosi asam nitrat 65\% mengalami penurunan nilai menjadi $57,330 \mathrm{kgf} / \mathrm{mm}^{2}$.

Tabel 2. Hasil Pengujian Tarik Baja Tahan Karat Austenitik 304

\begin{tabular}{|c|c|c|c|c|c|}
\hline \multirow{2}{*}{\multicolumn{3}{|c|}{$\begin{array}{l}\text { NOMOR } \\
\text { BENDA UJ }\end{array}$}} & \multicolumn{3}{|c|}{$\begin{array}{l}\text { HASIL PENGUJIAN TARIK } \\
\text { BAJA TAHAN KARAT AUSTENITIK } 304 \\
\left(\mathrm{kgf} / \mathrm{mm}^{2}\right)\end{array}$} \\
\hline & & & \multirow{2}{*}{\begin{tabular}{l}
\multicolumn{1}{l}{$\begin{array}{l}\text { TANPA } \\
\text { KOROSI }\end{array}$} \\
57,922
\end{tabular}} & \multirow{2}{*}{$\frac{\text { TERKOROSI } \mathrm{HNO}_{3} 65 \%}{60,107}$} & \multirow{2}{*}{$\frac{\text { TERKOROSI } \mathrm{HNO}_{3} 85 \%}{53,581}$} \\
\hline A & 1 & 6 & & & \\
\hline$B$ & 2 & 7 & 61,323 & 57,067 & 56,344 \\
\hline $\mathrm{C}$ & 3 & 8 & 61,171 & 58,41 & 55,027 \\
\hline $\mathrm{D}$ & 4 & 9 & 59,2 & 57,952 & 57,34 \\
\hline $\mathrm{E}$ & 5 & 10 & 60,917 & 53,113 & 54,451 \\
\hline \multicolumn{3}{|c|}{ RATA-RATA } & 60,107 & 57,330 & 55,349 \\
\hline
\end{tabular}

Hal yang sama pun terjadi apabila baja tahan karat Austenitik 304 terkorosi asam nitrat dengan konsentrasi larutan 85\%. Kekuatan tarik baja 
tahan karat Austenitik 304 semakin menurun menjadi 55,349 kgf $/ \mathrm{mm}^{2}$.

\section{Pengujian Persyaratan Analisis}

Untuk memenuhi persyaratan dalam pengujian hipotesis, terlebih dahulu dilakukan pengujian normalitas dan homogenitas varians.

1. Uji Normalitas.

Analisa yang digunakan untuk menguji normalitas data adalah uji Lilliefors. Data yang dianalisa adalah data nilai laju korosi baja tahan karat Austenitik 304 yang terkorosi asam nitrat $\left(\mathrm{HNO}_{3}\right)$ dengan konsentrasi larutan $65 \%$ dan data nilai laju korosi baja tahan karat Austenitik 304 yang terkorosi asam nitrat $\left(\mathrm{HNO}_{3}\right)$ dengan konsentrasi larutan $85 \%$.

Hasil pengujian normalitas dari data nilai laju korosi Austenitik 304 dengan asam nitrat $\left(\mathrm{HNO}_{3}\right) 65 \%$ menghasilkan $\mathrm{L}_{\circ}=0,1948$ dengan $\mathrm{n}$ sampel $=$ 5 , pada taraf nyata $(\alpha)=0,01$ diperoleh nilai $L_{\text {Tabel }}=0,405$, dengan kriteria pengujian apabila $L_{0}<L_{\text {Tabel }}$ maka data berdistribusi normal, dengan demikian dapat disimpulkan bahwa populasi kelompok berdistribusi normal.

Hasil pengujian normalitas dari data nilai laju korosi Austenitik 304 dengan asam nitrat $\left(\mathrm{HNO}_{3}\right)$ 85\% menghasilkan $\mathrm{L}_{0}=0,2641$ dengan $\mathrm{n}$ sampel $=5$, pada taraf signifikan $(\alpha)=0,01$ diperoleh nilai $L_{\text {Tabel }}=0,405$ dengan kriteria pengujian $L_{o}<L_{\text {Tabel }}$ maka data berdistribusi normal dengan demikian dapat disimpulkan bahwa populasi kelompok berdistribusi normal.

2. Uji Homogenitas.

Analisis statistik yang digunakan untuk menguji homogenitas adalah uji kesamaan dua varians (uji F). Data yang diuji adalah laju korosi batas butir dari masing-masing kelompok sampel. Dari perhitungan diperoleh $\mathrm{F}_{\text {Hitung }}=1,59$ , dengan taraf nyata $(\alpha)=0,01$ dari daftar distribusi $F$ dengan dk pembilang $=4$ dan dk penyebut $=4$ didapat $F_{0,01(4,4)}=15,98$ dan $F_{0,99(4,4)}=0,063$ sehingga

nilai $F$ berada diantara $F_{0,99(4,4)}<F_{\text {Hitung }}<F_{0,01(4,4)}$, maka dapat disimpulkan varians dari kedua kelompok homogen.

\section{Pengujian Hipotesis}

Untuk membuktikan hasil pengujian maka data di analisa dengan menggunakan uji kesamaan dua rata-rata (uji t), uji satu pihak, pihak kiri dengan hipotesis: $\mathrm{Ho}_{\mathrm{O}}: \mu 1=\mu 2$ 
Artinya tidak ada perbedaan antara kedua nilai laju korosi pada baja tahan karat Austenitik 304. $\mathrm{H} 1: \mu 1<\mu 2$, Artinya nilai rata-rata laju korosi antara yang menggunakan asam nitrat sebesar $65 \%$ lebih kecil dibandingkan dengan nilai korosi batas butir yang menggunakan asam nitrat $85 \%$ pada baja tahan karat Austenitik 304.

Dengan taraf signifikan $(\alpha)=0,01$ dimana $t_{\text {Hitung }}=-11,53$ dan $t_{\text {Tabel }}=\quad-$ 2,90 berarti $t_{\text {Hitung }}<\mathrm{t}_{\text {Tabel }}$ maka $\mathrm{H}_{\mathrm{o}}$ ditolak, sehingga nilai korosi batas butir baja tahan karat Austenitik 304 yang menggunakan asam nitrat $65 \%$ lebih kecil daripada nilai korosi batas butir baja tahan karat Austenitik 304 yang menggunakan asam nitrat $85 \%$.

Semakin besar presentase asam nitrat $\left(\mathrm{HNO}_{3}\right)$ yang dipakai sebagai media korosi pada baja tahan karat Austenitik 304, maka semakin besar pula nilai rata-rata laju korosinya. Hal ini berarti ketahanan baja tahan karat Austenitik 304 terhadap korosi semakin menurun sebagaimana ditunjukkan pada Tabel 3.

Tabel 3. Klasifikasi Laju Korosi

\begin{tabular}{|l|l|l|l|l|l|}
\hline \multirow{2}{*}{$\begin{array}{l}\text { Relative } \\
\text { Corrosion } \\
\text { Resultante }\end{array}$} & \multirow{2}{*}{$\mathrm{mpy}$} & $\mathrm{4pproximate}$ metric equivalent \\
\cline { 3 - 6 } & & $\mathrm{mm} / \mathrm{yr}$ & $\mu \mathrm{m} / \mathrm{yr}$ & $\mathrm{nm} / \mathrm{hr}$ & $\mathrm{pm} / \mathrm{sec}$ \\
\hline Outstanding & $<1$ & $<0,02$ & $<25$ & $<2$ & $<1$ \\
\hline Excellent & $1-5$ & $0,02-0,1$ & $25-100$ & $2-10$ & $1-5$ \\
\hline Good & $5-20$ & $0,1-0,5$ & $100-500$ & $10-50$ & $5-20$ \\
\hline Fair & $20-50$ & $0,5-1$ & $500-1000$ & $50-150$ & $50-200$ \\
\hline Poor & $50-200$ & $1-5$ & $1000-5000$ & $150-500$ & $50-200$ \\
\hline Unacceptable & $200+$ & $5+$ & $5000+$ & $500+$ & $200+$ \\
\hline
\end{tabular}

Sumber: M.G. Fontana, Corrosion Engineering (New York : Mc. Graw Hill Company Inc., 1986), hal. 133.

\section{KESIMPULAN DAN SARAN}

Berdasarkan hasil penelitian, maka dapat disimpulkan beberapa hal sebagai berikut :

1. Semakin besar presentase asam nitrat $\left(\mathrm{HNO}_{3}\right)$ yang dipakai sebagai media korosi pada baja tahan karat Austenitik 304, maka semakin besar pula nilai rata-rata laju korosinya. Hal ini berarti ketahanan baja tahan karat Austenitik 
304 terhadap korosi semakin menurun sebagaimana ditunjukkan pada tabel 3.

2. Baja tahan karat Austenitik 304 bila terekspos asam nitrat sebesar $65 \%$ akan menyebabkan baja tahan karat Austenitik 304 memiliki ketahanan yang minim dari serangan korosi. Dalam pengertian yang lain, bahwa pengeksposan asam nitrat $65 \%$ pada baja tahan karat Austenitik 304 merupakan batasan minimal memburuknya ketahanan baja tahan karat Austenitik 304 terhadap korosi.

3. Baja tahan karat Austenitik 304 bila terekspos asam nitrat sebesar $85 \%$ akan menyebabkan baja tahan karat Austenitik 304 tidak lagi memiliki ketahanan dari serangan korosi. Dalam pengertian yang lain, bahwa pengeksposan asam nitrat $65 \%$ pada baja tahan karat Austenitik 304 merupakan batasan maksimal (titik ultimate/ambang batas) memburuknya ketahanan baja tahan karat Austenitik 304 terhadap korosi.

4. Menurunnya kualitas baja tahan karat Austenitik 304 terhadap serangan karat, diikuti pula oleh menurunnya salah satu sifat mekanik baja tahan karat Austenitik 304 yaitu kuat tarik.

Berdasarkan kesimpulan, maka akan dikemukakan beberapa saran yang perlu disampaikan antara lain:

1. Pemakaian baja tahan karat Austenitik 304 untuk keperluan konstruksi hendaknya memperhatikan temperatur dan pengaruh asam yang bekerja di sekitar konstruksi.

2. Peneliti berharap dapat dilakukan penelitian lanjutan yang mengkaji perbandingan antara baja tahan karat Austenitik 304 yang dikorosikan dengan asam nitrat tanpa pembakaran (furnace) dan baja tahan karat Austenitik 304 yang dikorosikan dengan asam nitrat dengan pembakaran. Dengan demikian, dapat dilihat seberapa besar pengaruh temperatur memicu terjadinya korosi batas butir.

3. Dalam proses pemanasan benda uji selama pengkorosian, sebaiknya digunakan kompor gas daripada kompor listrik. Berdasarkan pengalaman penelitian, kompor listrik memiliki tingkat kestabilan yang rendah dalam pengontrolan temperatur. Sehingga tingkat kecelakaan dalam penelitian meningkat. 


\section{Daftar Pustaka}

Brown, Donald V.. Basic Metallurgy (Singapore : Delmar Publisher Inc.), 1981.

Beumer, B. J. M.. Ilmu Bahan Logam (Jakarta : Bharata Karya Aksara), 1985.

Dasmala, Asrul. Studi Tentang Mekanika Korosi Baja Karbon dalam Medium Air Laut di Indonesia LMN - LIPI Bandung (tidak dipublikasikan, Teknik Mesin IKIP Jakarta), 1986.

Davis and Associates. ASM Specialty Handbook: Stainless Steel (ASM International Hanbook Committee, January), 1996.

Faisal, Heny. Pengaruh Perlakuan Panas Terhadap Korosi Tegangan dan Sifat Mekanik Dari Baja Tahan Karat Austenitik 316 (tidak dipublikasikan, PPS UI), 1993.

Fontana, M. G.. Corrosion Engineering (New York : Mc Graw Hill Company Inc.), 1986.

Gruber, S.. Pengetahuan Bahan dalam Pengerjaan Logam, terjemahan Eddy D. H. (Bandung : Penerbit Angkasa), 1994.

Husein, Suryadi Hasan. Efek Korosi Akibat Deformasi Terhadap Sifat Mekanik Baja Anti Karat Austenitik AISI 304 (tidak dipublikasikan, PPS UI), 1996.

Saito, S., dan Surdia, Tata. Pengetahuan Bahan Teknik_(Jakarta : Pradnya Paramita), 1985.

Shigley, J. E., dan Michell, L. D.. Perencanaan Teknik Mesin Jilid I, terjemah Gandhi, H. (Jakarta : Erlangga), 1994.

Sulaiman, A.. Korosi Baja Pada Struktur Bangunan (Jakarta : Kumpulan Makalah LIPI), 1983.

Sedriks, J. A.. Corrosion Of Stainless Steel (New York : John Willey \& Son), 1996.

SNI 07-3112-1992. Uji Asam Nitrat untuk Deteksi Kerentanan Baja Terkorosi Antar Butir Baja Tahan Karat Austenitik (DSN), 1996.

Sudjana, Metode Statistika (Bandung : Tarsito), 1996.

Trethewey, K. R. dan Chamberlin, J.. Korosi Untuk Mahasiswa dan Rekayasawan, terjemahan Alex Tri K. W. (Jakarta : Gramedia), 1991.

Van Vlack, L. H.. IImu dan Teknologi Bahan, terjemahan Sriatie Djaprie (Jakarta : Erlangga), 1991.

Pengaruh Asam Nitrat Terhadap Laju Korosi Baja Tahan karat Austenitik 304 untuk Keperluan Konstruksi (MOS. Aritonang, Dosen Jurusan Teknik Sipil FT-UNJ) 